\title{
BMJ Open Study protocol of the COMPARE- Interaction study: the impact of maternal comorbid depression and anxiety disorders in the peripartum period on child development
}

\author{
Anna-Lena Zietlow, ${ }^{1}$ Christian Franz Josef Woll (10 , ${ }^{2}$ Nora Nonnenmacher, ${ }^{3}$ \\ Mitho Müller, ${ }^{2}$ Verena Labonte, ${ }^{2}$ Beate Ditzen, ${ }^{3}$ Markus Paulus, ${ }^{4}$ Beate Sodian, ${ }^{4}$ \\ Urs M Nater, ${ }^{5}$ Sabine C Herpertz, ${ }^{6}$ Corinna Reck ${ }^{2}$
}

To cite: Zietlow A-L, Woll CFJ, Nonnenmacher N, et al. Study protocol of the COMPAREInteraction study: the impact of maternal comorbid depression and anxiety disorders in the peripartum period on child development. BMJ Open 2022;12:e050437. doi:10.1136/ bmjopen-2021-050437

- Prepublication history for this paper is available online. To view these files, please visit the journal online (http://dx.doi. org/10.1136/bmjopen-2021050437).

\section{A-LZ and CFJW contributed} equally.

Received 25 February 2021 Accepted 07 December 2021

Check for updates

(C) Author(s) (or their employer(s)) 2022. Re-use permitted under CC BY-NC. No commercial re-use. See rights and permissions. Published by BMJ.

For numbered affiliations see end of article.

Correspondence to

Dr Anna-Lena Zietlow;

Zietlow@uni-mannheim.de

\section{ABSTRACT}

Introduction To date, there are only few studies that compare the consequences of peripartum maternal depressive disorders (PD) versus depressive with comorbid anxiety disorders (PDCA) for infant and child development. As comorbidity is associated with greater impairment and symptom severity related to the primary diagnosis, comorbidity in mothers might raise their offspring's risk of developing internalising or externalising disorders even more than has been noted in conjunction with PD alone. Methods and analysis This study aims to analyse the impact of parental psychopathology, particularly peripartum depression in mothers with and without comorbid anxiety disorders according to the Diagnostic and Statistical Manual of Mental Disorders (DSM-5) on child cognitive and socioemotional development. Maternal/ paternal psychopathology, mother-infant/father-infant interaction and child development are assessed at four measurement points over the first 2 years (T1: 3-4 months postpartum, T2: 12 months postpartum, T3: 18 months postpartum and T4: 24 months postpartum). The mediating role of mother-infant/father-infant interaction and infant stress reactivity in the relationship between PD/PDCA and infant cognitive and socioemotional development will be analysed. In the ongoing study, 174 families ( $\mathrm{n}=58$ mothers with $\mathrm{PD}, \mathrm{n}=58$ mothers with PDCA and $\mathrm{n}=58$ healthy controls) will be recruited in inpatient and outpatient centres as well as maternity hospitals in Munich and Heidelberg.

Ethics and dissemination This study is implemented in accordance with the current guidelines of the World Medical Association (revised Declaration of Helsinki) and the General Data Protection Regulation of the European Union. The study procedures were approved by the independent ethics committees of the Department of Psychology, Ludwig-Maximilians-University Munich (74_Reck_b) and of the Medical Faculty, University Heidelberg (S-446/2017). Participation is voluntary. A signed written informed consent form must be obtained from each study subject prior to any study-specific procedure. Participants can withdraw from the study at any point in time without giving a reason or being

\section{Strengths and limitations of this study}

- The proposed method is longitudinal and multimethodological, using behavioural, hormonal, developmental and clinical psychological measures from 3 to 24 months postpartum.

- The mediation analysis allows for a detailed examination of the quality of mother- and fatherchild-interaction and psychobiological variables contributing to the effect of maternal psychopathology on child development.

- Even though sample size is adequate for the proposed statistical analyses, the number of participants is limited due to the investigation of a clinical sample and does not allow to draw inferential conclusions about specific effects of individual anxiety disorders (and comorbid depression) on child development.

subjected to any future disadvantages. In case of withdrawal from the study, the subject's data and material will be kept unless the participant asks for data removal. Results will be published and disseminated to further the discussion on the effects of maternal PD and PDCA on parent-infant interaction, infant stress reactivity and child development. Furthermore, study results will be presented at international congresses and expert conferences.

\section{INTRODUCTION}

Peripartum depressive disorders (PD) and comorbid anxiety disorders (PDCA)

Peripartum depressive disorders (PD), showing prevalence rates of $6.1 \%$ considering the postpartum and $11.9 \%$ considering the peripartum period, ${ }^{1}$ and peripartum anxiety disorders (PA) with prevalence rates between $11.1 \%$ and $17.9 \%$ considering the postpartum period $^{23}$ are among the most frequent psychological disorders occurring around the time 
of childbirth. These disorders often coincide in around $50 \%$ of women, and the presence of a comorbidity can be considered as a marker of severity. ${ }^{4}$ The long-term adverse consequences for infant and child development are well documented in the literature.$^{5-7}$ Regarding child socioemotional development, the risk for transmitting depression $^{89}$ seems to be highest when both parents are affected (being up to four times higher).$^{10}$ The risk is lower if only the mother suffers from depression and is lowest if only the father is affected. ${ }^{11} 12$ This familial transmission has also been reported in association with anxiety disorders: ${ }^{13}$ The offspring's risk to develop an anxiety disorder is two to nine times higher. ${ }^{14}$ However, no research has yet addressed the impact and intergenerational transmission rates of peripartum depression with comorbid anxiety disorders (PDCA).

\section{Impact of maternal psychopathology on infants' cognitive and social-emotional development}

There is ample evidence of a long-lasting negative impact of PD on cognitive development, ${ }^{15}$ verbal abilities, ${ }^{16}$ executive functioning and memory capacity. ${ }^{17}$ Likewise, PD has been related to reduced socioemotional functioning and social-cognitive abilities in young children. For example, children of depressed mothers have been documented demonstrating less empathic concern towards others in distress, ${ }^{18}$ as well as less self-regulatory behaviour and more negative emotionality. ${ }^{19}$ However, there are studies that identified no effect of PD on children's caring behaviour. ${ }^{20}$ Regarding PA, longitudinal studies also refer to adverse effects on cognitive child development, partially up to adolescence. ${ }^{21} 22$ However, the impact of PDCA has not been adequately investigated to date.

Recent research on typical development has advanced our understanding of the predictive power of early socioemotional as well as cognitive development for the child's later social and cognitive functioning. ${ }^{23}{ }^{24}$ There has been little research on specific impairments stemming from maternal depression and anxiety disorders on the child's conceptual understanding of the mind and their potentially long-lasting effects on child social and cognitive functioning; the findings so far have been inconsistent. ${ }^{25} 26$

Studies reveal gender differences in the development of children whose mothers suffer from psychiatric disorders: the boys of mothers with depression seem to be particularly vulnerable to externalising behaviour problems, whereas higher rates of internalising symptoms have been reported in girls ${ }^{627}$ Furthermore, studies show that male children of depressed mothers are more impaired in their social and cognitive development than female children. ${ }^{27} 28$ Adverse developmental pathways, especially for cognitive development, have also been reported in male children of mothers with anxiety disorders. ${ }^{22}$ Nevertheless, the available studies are heterogeneous, and some studies detected no gender effects. ${ }^{17}$
Of particular importance seems to be evidence that the remission of psychiatric symptoms does not necessarily lead to an improvement in the quality of the motherchild relationship and interaction, and therefore, even remitted and lifetime diagnoses may exert negative longterm influence on child development. ${ }^{29} 30$

\section{Mediational relationship between maternal psychopathology and infant development}

Research about risk factors for child development lead to the assumption that infant and child developmental outcomes do not solely depend on maternal psychiatric disorders but rather that the quality of mother-child interaction is an important pathway for the intergenerational transmission of psychopathology. ${ }^{31} 32$ The interactive behaviour of depressed mothers is often characterised by a lack of sensitivity and responsiveness, passive or intrusive behaviour, a more negative and flat affect and withdrawn behaviour. ${ }^{33} 34$ Comorbid depressed and anxious mothers have revealed similar results, but empirical data are rather sparse. ${ }^{35}$ Regarding peripartum anxiety disorders (PA), mother-infant interactive behaviour studies also display heterogeneity: some suggest less sensitive and warm maternal interaction, ${ }^{19}{ }^{36}$ while others do not. ${ }^{5}$ Results of our own group with a sample of postpartum anxious mothers and their infants suggest links between maternal prepartum stress, infant stress reactivity and affect regulation during mother-child interaction up to preschool age. ${ }^{3738}$ It remains unclear whether these inconsistent results are due to different methodology and methodological problems (heterogeneous diagnoses within the anxious groups, varying questionnaires or interview data).

Empirical findings from several studies have highlighted the importance of specific patterns of parent-infant interaction for infants' affect regulation during the first 6 months. ${ }^{39}{ }^{40}$ Infants have a repertoire of self-regulatory behaviours believed to pacify their stressful experiences, but it is assumed that these behaviours do not fully suffice to handle distress. ${ }^{38}{ }^{41}$ Self-regulation in infancy includes the capacity to maintain positive states as well as manage distress and negative states. ${ }^{42}$ Caregivers are thought to play an important role in the development of stress regulation in infants. If the caregiver cannot (or does not) respond adequately to the child's emotion and interpersonal regulation failures, infants engage in self-directed stress regulation and develop less tolerance to negative affect and lower stress regulation competence. ${ }^{434}$

The hypothalamic-pituitary-adrenocortical (HPA) axis is one major regulating system to cope with stress on hormonal level. Its end product cortisol is intensively discussed as a key molecule in underlying mechanism accounting for the association between maternal stress and psychopathology during pregnancy and infant as well as child development. Research indicates that elevated maternal cortisol levels in response to stress may affect the offspring's HPA axis functioning. Consequences might be increased cortisol levels and increased cortisol 
reactivity ${ }^{45}$ and, in the long run, an increased risk for developmental problems in the offspring. ${ }^{46}$ Regarding infant stress reactivity and daytime cortisol during the first 18 months of life, infants of mothers with PDCA revealed relatively higher cortisol levels from morning to bedtime, higher bedtime values and heightened cortisol reactivity compared with infants of non-depressed mothers and infants of depressed mothers. Furthermore, cortisol's effects on infant development are moderated by the autonomic nervous system, with alpha-amylase as a key indicator of autonomic stress regulation. ${ }^{47} 48$

The role fathers play in child development during the peripartum period and early infancy in families with mothers suffering from PD and PDCA has not yet been examined. Our project offers a unique opportunity for further investigation. Sensitive fathers can be regarded as a protective factor for child development, a factor demonstrated in population-based and high-risk samples. ${ }^{49}$ However, if they are insensitive and unresponsive, for example, due to psychiatric symptoms, fathers might also be a risk factor for child development, with long-term negative consequences especially for socioemotional development..$^{50}$

To sum up, the negative impact of PD on infant socioemotional and cognitive development is well documented in the literature. To date, there are no studies comparing mothers with PD alone to mothers with PDCA. As comorbidity goes along with greater impairment and symptom severity related to the primary diagnosis, comorbidity in mothers might raise their offspring's risk of developing internalising disorders even more than has been noted in conjunction with PD alone. This study is designed to assess mothers with PD and PDCA according to the Diagnostic and Statistical Manual of Mental Disorders (DSM5), fathers and their infants, as well as a healthy control group (CG) at four measurement times (see figure 1). The study will be run in Munich and Heidelberg. Given the high prevalence of PD and PA and the increased risk for children of depressed and anxious mothers to having adverse developmental problems, further research in this field is urgently needed.

\section{The planned trial}

The following relations will be investigated in this observational longitudinal study.

1. We hypothesise that the degree of maternal disorder severity correlates with greater impairment in infant development at 12, 18 and 24 months.

2. We hypothesise that both, mother-infant/father-infant interaction and infant stress reactivity at 12 months of infant age, mediate the relationship between the maternal disorder severity at 3-4 months postpartum and infant socioemotional as well as cognitive development at 24 months of age. Thus, we will analyse a mediating effect of mother-infant/father-infant interaction and infant stress reactivity on infant cognitive and socioemotional development in the context of maternal disorder severity.

Moreover, research shows that patterns of couple interaction are predictive for later parent-child interaction. ${ }^{52}$ Therefore, additional dyadic analyses will include couple interaction, the couples' heart rate variability (HRV) and the couples' cortisol reactivity during an instructed conflict discussion in the laboratory at the infants' age of 3-4 months. It is assumed that the parents' individual and couple-based stress responses during couple interactions in the child's early life serve as possible mediators for the relationship between maternal PD and PDA and child development. In the current study, neuroendocrine and psychobiological mediators of this relationship will be captured during instructed real-time interactions. Furthermore, maternal blood samples are taken to examine the endogenous oxytocin level, gonadal hormones and epigenetic parameters of the oxytocin gene and oxytocin receptor gene. Additional analyses will further address the relation between maternal psychopathology, parent-infant interaction and HRV of mother/father and child during dyadic interaction at 3-4, 12 and 24 months. We will focus on the analysis of the synchrony between cortisol reactivity, HRV during dyadic interaction and interactional behavioural patterns. These analyses will be conducted in an exploratory manner to generate hypotheses for future research.

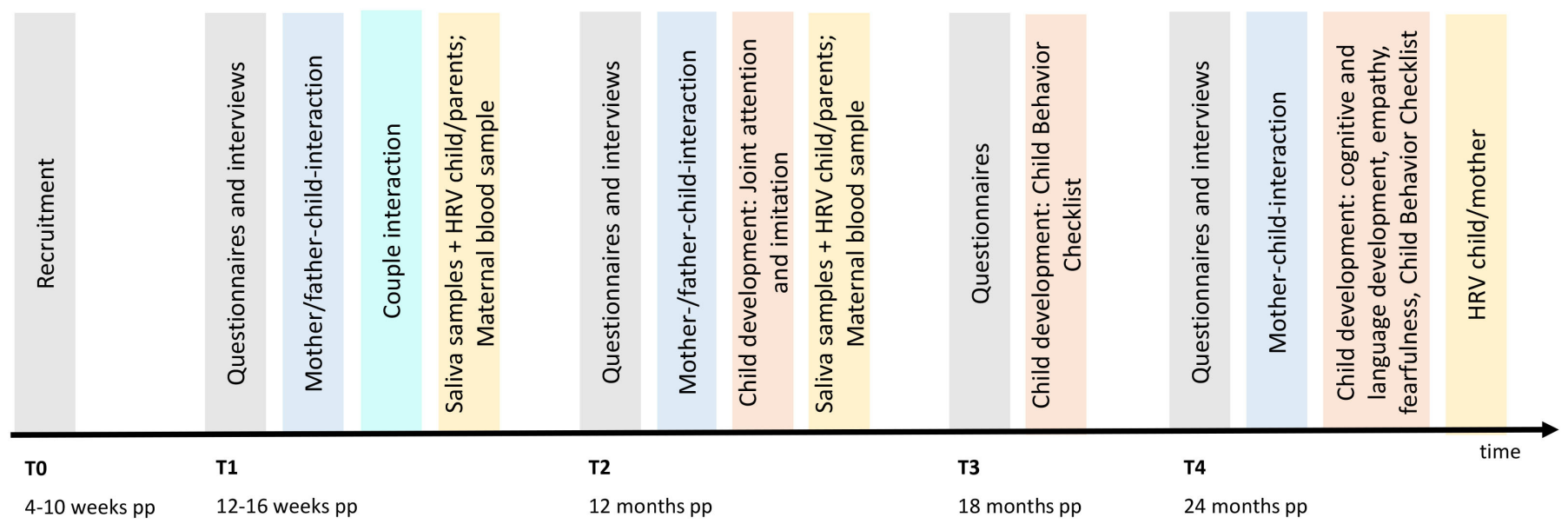

Figure 1 Overview of study design. HRV, heart rate variability. 
In summary, this study will address the influence of maternal PD and PDCA on infant and child development with a special focus on the mediating effects of parentinfant interaction and infant stress reactivity. Our findings will contribute to better understand the underlying mediating effects, which may help to further improve prevention and intervention approaches.

\section{METHODS AND ANALYSIS Design overview}

In order to investigate the previously mentioned points 1 and 2, an observational longitudinal study will be implemented. As the two clinical groups ((1) PDCA and (2) PD)) and the CG are formed based on the mother's mental health status, our study design can be characterised as a natural experiment. The three groups will be accompanied throughout the infants' first 2 years of life and to be more precise throughout four different measurement points at the infants' age of 3-4 (T1), 12 (T2), 18 (T3) and 24 (T4) months. See figure 1 for an overview (figure 1).

Our primary outcome measures include infant socioemotional development, more specifically internalising and externalising behaviour problems assessed with the Child Behavior Checklist (CBCL), ${ }^{53}$ and cognitive development assessed with the cognitive scale of the Bayley's Infant Development Scale III ${ }^{54}$ at 24 months postpartum. Maternal interaction quality 12 months postpartum, more precisely maternal sensitivity coded via the Coding Interactive Behavior, as well as infant-cortisol reactivity at 12 months of age are considered as primary mediators.

In the exploratory analyses, infant gender is considered as a moderator for the interactive mediational path ${ }^{55}$ while for the mediation by infant stress reactivity, infant gender ${ }^{56}$ and alpha-amylase ${ }^{47}$ are considered as moderators.

Our secondary outcome measures are imitation and joint attention at 12 months as well as empathy, language development and child fearfulness at 24 months. Secondary mediators are further interactional qualities (eg, exploration, intrusiveness and limit setting) as well as father-infant interaction (eg, sensitivity, exploration, intrusiveness and limit setting).

\section{Participant eligibility and recruitment}

Eligible participants

Clinical groups: subjects need to fulfil the DSM-5 criteria for a PD or for a PDCA, meaning the DSM-5 criteria have to be fulfilled at a time from the beginning of the pregnancy until the end of the fourth month postpartum.

Controls need to have no current or lifetime diagnosis and should not have received psychotherapy or more than seven therapeutic counselling sessions at any time in their life. Seven sessions represented the maximum length of diagnostics for psychotherapy in the German healthcare system.

\section{Exclusion criteria for all groups}

Mothers: acute suicidality, current or lifetime diagnosis of psychosis and bipolar disorder (one psychotic episode during the puerperium is not an exclusion criterion); diagnosed substance use disorder since they have become aware of their pregnancy

Infants: preterm birth defined as gestational age at birth of less than 36 weeks and 1 day; multiple birth infants; less than seven points in any of the three APGAR scores $(1,5$ and $10 \mathrm{~min}$ after birth); and confirmed physical or developmental disorders, which make participation impossible or unwise.

\section{Participant recruitment}

Participants will be recruited both online and by flyers disseminated through midwives, gynaecologists, paediatricians, in pharmacies and in maternity hospitals as well as mothering forums or self-help groups (eg, 'Shadow and Light') and registration offices in Munich and Heidelberg. They receive thorough information about the study procedures both orally and in written form. We estimate that 1.447 mothers per year can be asked to participate in our study (considering an annual birth rate of 15.000 infants in Munich and 4.300 in Heidelberg/Mannheim, a prevalence rate of $6 \%$ for PD and $11 \%$ for PA and an estimated rate of $50 \%$ of mothers seeking help). In order to avoid high rates of non-participations due to feelings of self-blame, which is often recognised in $\mathrm{PD},{ }^{57}$ the recruitment material and procedure is designed and conducted cautiously and empathetically.

The COMPARE study started in January 2018, but recruitment for the first test interval $\mathrm{T} 1$ has not been completed yet. A percentage of 64.4 of the required participants (112 of 174) have been recruited so far. The fourth test interval T4 started in March 2020. The total assessment status of the longitudinal study can, therefore, be described as less than half of the procedure. Additionally, since March 2020, recruitment and assessment have been partly delayed by the coronavirus pandemic.

\section{Participant and public involvement}

Participants or the public were not involved in the design or implementation of this study. The results will not be disseminated to the participants directly, but the anonymised data will be openly accessible in the Open Science Framework.

\section{Screening assessment and group allocation Screening assessment}

Participants will take part in a screening procedure via a phone interview prior to inclusion.

\section{Group formation procedure}

According to our natural experimental design, the formation of the three groups: PD, PDCA and CG is based on the outcome of the clinical interview (DSM-5) conducted at $\mathrm{T} 1$. 


\section{Power analysis and size estimation}

Sample size was estimated for the regression-based mediation model (see point 2 of 'The Planned Trial') with MedPow.R using 'R' (V.3.3.2) ${ }^{58}$ with 'R-Studio' (V.1.0.44). Therefore, a c' path with a direct effect of 0.00 was scheduled. As we assume to find effects of medium size, ${ }^{59}$ we concluded an effect of $r=0.30$ for paths a and $\mathrm{b}$. As two models will be calculated (one for socioemotional development and one for cognitive development), we considered a Bonferroni-adjusted two-sided $\alpha$-error of 0.025 . We aim to achieve a power of $1-\beta=0.80$. We thus estimate the study sample size to include 135 subjects. As the actual mediation model contains two mediators, the pursued number of cases presents a minimum of the necessary study sample size. Furthermore, we anticipate a conventional study drop-out rate of $20 \%$. Thus, overall, 174 mother-infant dyads will have to be recruited (thus, $n=58$ per subgroups and $n=87$ per study centre in Heidelberg and Munich).

\section{Experimental procedure at $\mathrm{T} 1, \mathrm{~T} 2, \mathrm{~T} 3$ and $\mathrm{T} 4$}

At measurement point T1 (3-4 months), mothers' and fathers' psychological health will be assessed via the clinical interview for DSM-5. ${ }^{60} 61$ Clinical screenings will be repeated at 12 months (T2) and 24 months (T4). In April 2020, we expanded the clinical interviews and screenings by a standardised questionnaire assessing the families' situation during the coronavirus pandemic. Parent-infant interaction at T1 will be measured by the Face-to-Face Still-Face experiment, ${ }^{62}$ which will be videotaped. In order to measure the level of cortisol and alpha-amylase, saliva samples of the infants will be taken before and directly after as well as 20 and $30 \mathrm{~min}$ after the starting point of the Face-to-Face Still-Face experiment. Additionally, heart rates of the infants and the caregivers will be recorded during dyadic interaction. The couple interaction at T1 will consist of a $15 \mathrm{~min}$ conversation about two couple issues chosen by the couple from a standardised list in advance. ${ }^{63}$ The parents' saliva will be collected before and directly after as well as 30 and $45 \mathrm{~min}$ after the starting point of the couple interaction. Moreover, parental heart rate will be measured during couple interaction. Furthermore, maternal blood samples will be collected at the beginning of the assessment point in order to measure endogenous oxytocin level, gonadal hormones and epigenetic parameters of the oxytocin gene and oxytocin receptor gene. At T2, the parent-infant interaction will be conducted in form of a $13 \mathrm{~min}$ free play situation including a $3 \mathrm{~min}$ limit setting task. Again, infants' salvia samples will be collected before, directly after as well as 28 and $38 \mathrm{~min}$ after the interaction experiment. Moreover, the infants will take part in an imitation ${ }^{64}$ and two joint attention tasks. ${ }^{65}{ }^{66}$ Again, maternal blood samples will be collected. At T3 and T4, infant behaviour and development will be measured by the $\mathrm{CBCL}^{53}$ and the CaregiverTeacher-Report Form ${ }^{67}$ filled out by the parents and an additional caregiver. At T4, an 11 min free play situation including a $1 \mathrm{~min}$ frustration task will be conducted.
Additionally, infant cognitive and socioemotional development will be assessed. All assessments will be video recorded and coded afterwards. See figure 1 and table 1 for an overview of the study design and the measures for each measurement point. For all measurement points, a time frame for assessment of 4 weeks will be accepted (T1: 3 months and 0 days to 3 months and 30 days; T2-4: $12 / 18 / 24$ months \pm 14 days).

\section{Detailed description of measures, methods and instruments used \\ Interactional measures \\ Parent-infant interaction \\ Face-To-Face Still-Face paradigm (T1)}

At T1, parent-infant interaction will be assessed during the Face-to-Face Still-Face paradigm, a widely used paradigm for evaluating the quality of early parent-infant interaction. ${ }^{62}$ It consists of three episodes each lasting $2 \mathrm{~min}$ : first, an initial face-to-face interaction in which the mothers/fathers are instructed to play with their infant as usual (without the aid of toys and pacifiers). Next, the still-face episode follows in which the parents have to turn their head aside while silently counting to ten and then turn back to the infant but not engage in any gestures, facial expressions or vocalisations. Finally, the procedure ends with the reunion episode in which the parent is required to resume face-to-face play with the infant.

\section{Free play and limit setting task (T2)}

This interactional task consists of three episodes: in episode 1, lasting $5 \mathrm{~min}$, mother/father and child engage in a free play with a given set of toys. In episode 2, the mother/father is asked to take place in a seat in some distance to the child and to focus on a newspaper for $3 \mathrm{~min}$. In episode 3 , the mother/father can reunite with the child in a free play lasting $5 \mathrm{~min}$.

\section{Free play and frustration task (T4)}

In this interactional paradigm, mother and child engage in a $10 \mathrm{~min}$ free play with a given set of toys. After $10 \mathrm{~min}$, they are requested to clean up all toys for $1 \mathrm{~min}$.

\section{Couple interaction}

During $\mathrm{T} 1$, in order to evaluate the influence of the quality of the parental relationship, couple interaction behaviour will be assessed during a 15 min standard and instructed discussion. ${ }^{63}$ As in previous experimental designs, ${ }^{68-70}$ the parents are asked to rate the intensity of 23 predetermined areas of couple conflict with regard to their own relationship. They then chose two topics (eg, finances, educational issues and leisure time) of continuing disagreement for the later discussion, which is videotaped and coded for behaviour.

\section{Coding scheme for the interactional paradigms}

All interaction sequences (parent-infant/child interaction and couple interaction) will be coded following the coding interactive behaviour manual (CIB) developed by Ruth Feldman. The couple conflict discussion 
Table 1 Schedule of measures used in the study

\begin{tabular}{|c|c|c|c|c|c|}
\hline Measures & Citation & T1 & T2 & T3 & T4 \\
\hline \multicolumn{6}{|l|}{ Interactional measures } \\
\hline \multicolumn{6}{|l|}{ Mother-infant interaction } \\
\hline Free play+limit setting & & & $x$ & & \\
\hline Free play+frustration task & & & & & $x$ \\
\hline Face-to-Face Still-Face Paradigm & 62 & $x$ & & & \\
\hline Free play+limit setting & & & $x$ & & \\
\hline \multicolumn{6}{|l|}{ Couple interaction } \\
\hline Topic suggestions for discussion and follow-up questionnaire & 63 & $x$ & & & \\
\hline \multicolumn{6}{|l|}{ Psychobiological measures } \\
\hline Couple HRV & & $\times$ & & & \\
\hline Child cortisol and alpha-amylase saliva sample & & $\times$ & $x$ & & \\
\hline Parental cortisol and alpha-amylase saliva sample & & $\times$ & & & \\
\hline \multicolumn{6}{|l|}{ Interviews } \\
\hline Diagnostic interview for mental disorders according to DSM 5 & 61 & $\times$ & & & \\
\hline Attachment style interview & 75 & $x$ & & & \\
\hline
\end{tabular}

\section{Sociodemographic details}

Edinburgh Postnatal Depression Scale

Agoraphobic Cognitions Questionnaire, Body Sensations Questionnaire 85 and Mobility Inventory

Postpartum Bonding Questionnaire 16R

86

Lips Maternal Self-Confidence Scale

Partnership Questionnaire

$x$

Social Support Questionnaire

Dyadic Coping Inventory

87

Remembered parenting behaviours (Fragebogen zum erinnerten

88

elterlichen Erziehungsverhalten)

Parental Bonding Instrument

Experiences in Close Relationships-Revised

Infant Behaviour Questionnaire

Personality Inventory for DSM-5 - Brief Form

Childhood Trauma Questionnaire

\section{Parenting Stress Index}

Vulnerable Attachment Style Questionnaire

Parenting styles (Erziehungsfragebogen für Eltern)

Epistemic Trust Questionnaire

Parental Reflective Functioning Questionnaire

89

$x \quad x \quad x$




\begin{tabular}{|c|c|c|c|c|c|}
\hline Measures & Citation & T1 & T2 & T3 & T4 \\
\hline Child fearfulness & 79 & & & & $\times$ \\
\hline Language assessment (Sprachentwicklungstest für zweijährige Kinder) & 77 & & & & $\times$ \\
\hline Bayley's Infant Development Scale III & 54 & & & & $\times$ \\
\hline Child Behaviour Checklist & 53 & & & $x$ & $\times$ \\
\hline Caregiver-Teacher Report Form & 67 & & & $x$ & $\times$ \\
\hline
\end{tabular}

DSM 5, Diagnostic and Statistical Manual of Mental Disorders; HRV, heart rate variability; T1, first measurement point; T2, second measurement point; T3, third measurement point (online assessment); T4, fourth measurement point.

will also be coded with the CIB, which was extended for couple interaction. The CIB is a widely used, macroanalytic rating system for analysing dyadic interaction. The system uses multiple codes for the infants, parents and dyadic codes that aggregate into meaningful theoretically based constructs (eg, sensitivity, intrusiveness, reciprocity, social engagement and withdrawal). The psychometric characteristics are all well described. ${ }^{71}$ Microanalytically, the parent-infant interaction episodes of $\mathrm{T} 1$ will be coded with the German translation and revision of the Infant and Caregiver Engagement Phases (ICEP-R). ${ }^{72}$ The ICEP-R phases combine information from the face, direction of gaze and vocalisations of the infants and caregivers. We will code the videos using the Mangold Interact coding software with $1 \mathrm{~s}$ time intervals.

The interaction sequences will be coded by blind and reliable coders who are independent of the current study; $10 \%-20 \%$ of the videos will be double coded for interrater reliability.

\section{Psychobiological measures \\ Maternal blood samples}

Maternal blood samples are taken to examine the endogenous oxytocin level, gonadal hormones and epigenetic parameters of the oxytocin gene and oxytocin receptor gene.

\section{Infant stress reactivity}

To determine infant stress reactivity, cortisol and alphaamylase will be extracted from infant saliva, which will be collected according to standard protocols ${ }^{73}$ during all interaction paradigms at T1 and T2. Saliva is collected before (C1) and after (C2) as well as $20 \mathrm{~min}$ (C3) and 30 min (C4) after the starting point of the Face-to-FaceStill-Face paradigm at T1, and likewise before and after, as well as 28 and $38 \mathrm{~min}$ after the starting point of the interactional paradigms at T2. Following analytic procedures, ${ }^{74}$ the area under the curve with respect to increase $\left(\mathrm{AUC}_{\mathrm{I}}\right)$ will be calculated as an index for infant cortisol reactivity. This measure is the integral of the curve resulting from the four cortisol measures (C1, C2, C3 and C4) and denotes the time distance between measurements, in contrast to statistical tests for repeated measures. $\mathrm{AUC}_{\mathrm{I}}$ is calculated with reference to the first value (C1) and therefore measures the change over time.

\section{Parental stress reactivity}

As described previously, parental stress reactivity (cortisol and alpha-amylase) will be collected via saliva samples, before, directly, 30 and 40 min after the couple interaction paradigm.

\section{Infants' and caregivers' HRV}

As a cardiovascular measure of the emotion regulation capacity, the HRV of the caregiver and infant will be measured during the Face-to-Face-Still-Face paradigm, the limit setting task and the frustration task at T1, T2 and T4. HRV will be conducted with a one-electrode sensor (eMotion Faros $90^{\circ}$, Sampling Rate $250 \mathrm{~Hz}$ ) and is calculated via $\mathrm{R}-\mathrm{R}$ intervals $(\mathrm{HR} / \mathrm{min}=60.000 \mathrm{~ms} / \mathrm{min} / \mathrm{R}-\mathrm{R}$ intervals per ms). The analysis will be calculated with Kubios HRV (V.2.0) concentrating on respiratory sinus arrhythmia.

\section{Parental HRV}

According to the analyses of parent-infant HRV, the parental HRV will be assessed during couple interaction at $\mathrm{T} 1$.

\section{Diagnostic measures}

Diagnostic Interview for Mental Disorders according to DSM-5 (DIPS-OA)

In this study, participants' mental disorders will be assessed with a structured clinical interview, the Diagnostic Interview for Mental Disorders according to DSM 5 (DIPS-OA). ${ }^{60}{ }^{61}$ It assesses lifetime, as well as current and past diagnoses. All clinical assessments will be conducted by trained and experienced psychologists.

\section{Attachment Style Interview (ASI)}

This semistructured interview focuses on current behaviour and attitudes to assess adult attachment, including secure, anxious (enmeshed or fearful) and avoidant (angry-dismissive or withdrawn) attachment styles. Dual/disorganised attachment style is characterised by a 'double' classification of style, occurring when no clear attachment pattern can be recognised. In order to assure the quality of the ratings, $10 \%-20 \%$ randomly selected tapes will be double coded by two independent study coders. ${ }^{75}$ 


\section{Infant and child development}

Cognitive development

Cognitive development will be assessed at T4 using the cognitive scale of the Bayley Scales of Infant Development- III. ${ }^{54}$ The Bayley Scales allow for the assessment of infants' and toddlers' development between 1 and 42 months of age. The Bayley-III indices and subscales demonstrate good internal consistency and good split-half consistency according to the Spearman-Brown formula. ${ }^{76}$ Regarding construct validity, confirmatory factor analysis of the subtests of the cognitive, language, and motor scales supported a three-factor model across all ages. The Bayley-III scales have been normed for German infants and children. ${ }^{54}$

\section{Language abilities}

For the assessment of language abilities (verbal understanding and language production), we will administer a standardised German language test for children aged 2 years (Sprachentwicklungstest, SETK-2). ${ }^{77}$ The duration of use is about $15-20 \mathrm{~min}$. It has been found to have a (mostly) high validity and reliability (with Cronbach's alpha between 0.56 and 0.95 for the four subscales).

Cognitive and socioemotional development: joint attention, imitation, child fearfulness and empathy

At the age of 12 months, we will assess gaze and point following, ${ }^{65}$ declarative and imperative point production and understanding, ${ }^{66}$ and imitation of object-related and intransitive action skills as predictors of later sociocognitive development. ${ }^{64}$ This will be expanded on at 24 months by an assessment of empathy as a milestone of constructive social behaviour ${ }^{78}$ and of child fearfulness (spider task). ${ }^{79}$

Socioemotional development: CBCL/Caregiver Teacher Report Form At T3 and T4, parents and additional caregivers will rate the children's socioemotional development by filling out the Child Behaviour Checklist/Caregiver Teacher Report Form. ${ }^{5367}$ These measures assess internalising and externalising behaviour problems in children $(0=$ absent, $1=$ occurs sometimes, $2=$ occurs often). Internalising behaviour includes emotional reactive behaviour, anxious/depressive symptoms, somatic complaints and withdrawn behaviour, whereas attention deficits and aggressive behaviour are characteristics for externalising behaviour. In both questionnaires, higher scores indicate more problematic child behaviour. T-scores above 60 can be seen as clinically relevant. Psychometric properties are described as satisfying.

\section{Data analysis plan}

Statistical analyses will be conducted using the Statistical Package for Social Sciences (IBM SPSS current V.27.0.0.0) and R (current V.4.0.1). ${ }^{58}$ We will carry out conditional process analyses using the SPSS-Macro 'PROCESS' (current V.3.5). ${ }^{80}$ We will analyse the model depicted in figure 2. The SEs and CIs of the indirect (mediated) effects will be bootstrapped and bias corrected $(n=5000$ samples). Variables will be mean centred. Estimates will be tested two tailed (critical $\alpha=0.025$; Bonferroni adjusted for two primary outcomes of child development). According to our hypotheses, a significant initial direct pathway e of our conditional process analyses will reflect the association between maternal disorder severity, which will be coded by the ordinal variable in the following order: CG: 0, PD: 1 and PDCA: 2, and child development, that is, the higher the ordinal coded variable, the more impaired child development (hypothesis $1)$. Concerning the parallel mediators, we expect significant indirect pathways $\mathrm{a} * \mathrm{~b}$ and $\mathrm{c}^{*} \mathrm{~d}$, that is, the higher the ordinal coded variable, the lower the maternal sensitivity/the higher the infant cortisol reactivity, the more impaired child development (hypothesis 2). Mediators will be allowed to correlate in our analyses. Moreover, the differences between the groups will be explored by applying one-factorial (multivariate) analyses of variance (MANOVA and ANOVA).

All metric variables will be preliminarily analysed for normal distribution (Kolmogorov-Smirnov and ShapiroWilk tests), linearity (scatterplots), homoscedasticity (scatterplots) and independence (Durbin-Watson coefficient). The unit of analyses is the caregiver-infant dyad.

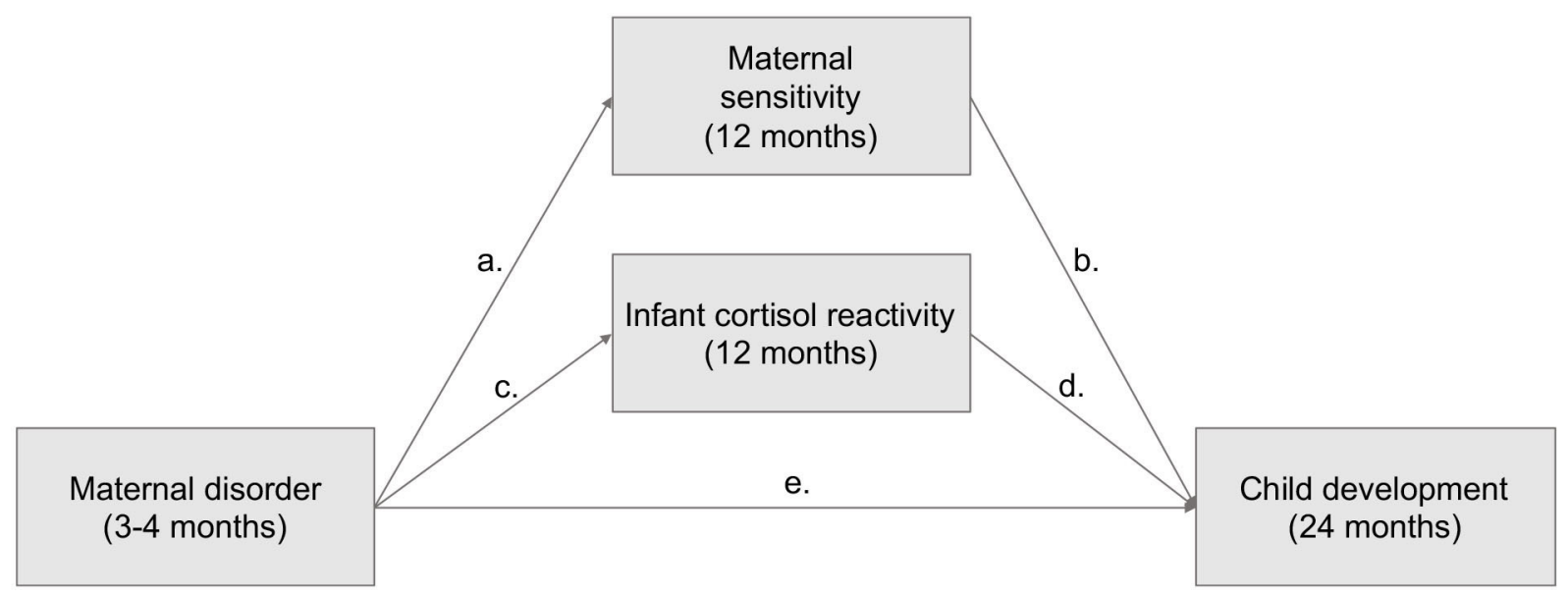

Figure 2 Mediation model. 
In case of missing values and incomplete cases, we will determine whether the missing completely at random (MCAR) condition is fulfilled by using Little's MCAR test. ${ }^{81}$ If non-significant, missing values are unlikely to depend on third variables and will be estimated using multiple imputations ${ }^{82}$ according to standard practice. ${ }^{83}$

\section{DISCUSSION}

PDCA and PD may influence infant and child cognitive and socioemotional development. The quality of caregiver-infant interaction is said to play a crucial role in this transmission process. To our best knowledge, our study is the first one to address the impact of PDCA and PD on child development on a behavioural, hormonal, developmental and clinical psychological level in a longitudinal design. Our multimethodological approach casts a wide net of possible linkages that allow broad and comprehensive analyses in an exploratory manner. A focus, however, will be laid on the effects of PDCA and PD on children's internalising and externalising behaviour problems as well as on their cognitive development at 24 months postpartum. In this context, we focus on the mediating role of maternal sensitivity and infant-cortisol reactivity at 12 months of age. The identification of specific behavioural and psychobiological patterns might further inform prevention and intervention approaches. A unique strength of our study is the inclusion of fathers, allowing to view families from an overall perspective and to examine their role as a possible buffer in the family system. An acknowledged study limitation can be seen in the number of participants that represents an adequate sample size for our proposed statistical analyses is too small, though, to draw differential conclusions about individual anxiety disorders.

\section{ETHICS AND DISSEMINATION}

\section{Ethics, consent to participate and dissemination}

This study is implemented in accordance with the current guidelines of the World Medical Association (revised Declaration of Helsinki) and the General Data Protection Regulation of the European Union (EU-GDPR). The study procedures were approved by the independent ethics committees of the Department of Psychology, Ludwig-Maximilians-University Munich (74_Reck_b) and of the Medical Faculty, University Heidelberg (S-446/2017). Participation is voluntary. A signed written informed consent form must be obtained from each study subject prior to any study-specific procedure. Participants can withdraw from the study at any point in time without giving a reason or being subjected to any future disadvantages. In case of withdrawal from the study, the subject's data and material will be kept unless the participant asks for data removal.

Results will be internationally published and disseminated to further the discussion on the effects of maternal $\mathrm{PD}$ and PDCA on parent-infant interaction, infant stress reactivity and child development. Furthermore, study results will be presented at international congresses and expert conferences.

\section{Author affiliations}

1Department of Psychology, School of Social Sciences, University of Mannheim, Mannheim, Germany

2Department of Psychology, Clinical Psychology of Children and Adolescents, Ludwig-Maximilians-University Munich, Munich, Germany

${ }^{3}$ Institute of Medical Psychology, Centre of Psychosocial Medicine, Heidelberg University, Heidelberg, Germany

${ }^{4}$ Department of Psychology, Developmental and Educational Psychology, LudwigMaximilians-University Munich, Munich, Germany

${ }^{5}$ Department of Psychology, University of Vienna, Vienna, Austria

${ }^{6}$ Department of General Psychiatry, Centre of Psychosocial Medicine, Heidelberg University, Heidelberg, Germany

Acknowledgements The authors wish to thank Britta Zipser, Nina Schlegel, Hannah-Sophie Lässig, Josephine Parol, Ines Brenner, Carina Schildberg, Elena Siegler, Sophia Wriedt-Monske, Nadine Korus, Anamaria Semm, Nele Harbrecht, Lena Streckert, Sophie Koller, Evamaria Ehrmann, Moritz Birkendahl and Sarah Ghezih as well as all involved students and interns for their assistance with conducting the study.

Contributors A-LZ, CR, NN, MM, BD, BS, MP, UMN and SCH designed the study. CR and A-LZ lead the study; NN, CFJW and VL established the study set-up and will collect data. A-LZ, CFJW and NN wrote and edited the manuscript; all authors provided comments on the manuscript.

Funding This work was supported by the Federal Ministry of Education and Research of Germany (grant number: 01GL1748D). The publication of this article was funded by the Baden-Württemberg Ministry of Science, Research and the Arts and by the University of Mannheim.

Competing interests None declared.

Patient and public involvement Patients and/or the public were not involved in the design, or conduct, or reporting, or dissemination plans of this research.

Patient consent for publication Not applicable.

Provenance and peer review Not commissioned; externally peer reviewed.

Open access This is an open access article distributed in accordance with the Creative Commons Attribution Non Commercial (CC BY-NC 4.0) license, which permits others to distribute, remix, adapt, build upon this work non-commercially, and license their derivative works on different terms, provided the original work is properly cited, appropriate credit is given, any changes made indicated, and the use is non-commercial. See: http://creativecommons.org/licenses/by-nc/4.0/.

\section{ORCID iD}

Christian Franz Josef Woll http://orcid.org/0000-0002-0352-4796

\section{REFERENCES}

1 Woody CA, Ferrari AJ, Siskind DJ, et al. A systematic review and meta-regression of the prevalence and incidence of perinatal depression. J Affect Disord 2017;219:86-92.

2 Reck C, Struben K, Backenstrass M, et al. Prevalence, onset and comorbidity of postpartum anxiety and depressive disorders. Acta Psychiatr Scand 2008;118:459-68.

3 van de Loo KFE, Vlenterie R, Nikkels SJ, et al. Depression and anxiety during pregnancy: the influence of maternal characteristics. Birth 2018;45:478-89

4 Penninx BWJH, Nolen WA, Lamers F, et al. Two-year course of depressive and anxiety disorders: results from the Netherlands study of depression and anxiety (NESDA). J Affect Disord 2011;133:76-85.

5 Glasheen C, Richardson GA, Fabio A. A systematic review of the effects of postnatal maternal anxiety on children. Arch Womens Ment Health 2010;13:61-74.

6 Goodman SH, Rouse MH, Connell AM, et al. Maternal depression and child psychopathology: a meta-analytic review. Clin Child Fam Psychol Rev 2011;14:1-27.

7 Oyetunji A, Chandra P. Postpartum stress and infant outcome: a review of current literature. Psychiatry Res 2020;284:112769. 
8 Ulrich I, Stopsack M, Spitzer C. Familiäre transmission depressiver Störungen: die Bedeutung von Schadensvermeidung. Nervenarzt 2011;82:1169-77.

9 Gotlib IH, Goodman SH, Humphreys KL. Studying the intergenerational transmission of risk for depression: current status and future directions. Curr Dir Psychol Sci 2020;29:174-9.

10 Nomura Y, Warner V, Wickramaratne P. Parents concordant for major depressive disorder and the effect of psychopathology in offspring. Psychol Med 2001;31:1211-22.

11 Connell AM, Goodman SH. The association between psychopathology in fathers versus mothers and children's internalizing and externalizing behavior problems: a meta-analysis. Psychol Bull 2002;128:746-73.

12 Tan S, Rey J. Depression in the young, parental depression and parenting stress. Australas Psychiatry 2005;13:76-9.

13 Lieb R, Wittchen HU, Höfler M, et al. Parental psychopathology, parenting styles, and the risk of social phobia in offspring: a prospective-longitudinal community study. Arch Gen Psychiatry 2000;57:859-66.

14 Micco JA, Henin A, Mick E, et al. Anxiety and depressive disorders in offspring at high risk for anxiety: a meta-analysis. J Anxiety Disord 2009;23:1158-64.

15 Koutra K, Chatzi L, Bagkeris M, et al. Antenatal and postnatal maternal mental health as determinants of infant neurodevelopment at 18 months of age in a mother-child cohort (Rhea Study) in Crete, Greece. Soc Psychiatry Psychiatr Epidemiol 2013;48:1335-45.

16 Quevedo LA, Silva RA, Godoy R, et al. The impact of maternal postpartum depression on the language development of children at 12 months. Child Care Health Dev 2012;38:420-4.

17 Vänskä M, Punamäki R-L, Tolvanen A. Maternal pre- and postnatal mental health trajectories and child mental health and development: prospective study in a normative and formerly infertile sample. Int $J$ Behav Dev 2011;35:517-31.

18 Jones NA, Field T, Davalos M. Right frontal EEG asymmetry and lack of empathy in preschool children of depressed mothers. Child Psychiatry Hum Dev 2000;30:189-204.

19 Feldman R, Granat A, Pariente C, et al. Maternal depression and anxiety across the postpartum year and infant social engagement, fear regulation, and stress reactivity. J Am Acad Child Adolesc Psychiatry 2009;48:919-27.

20 Radke-Yarrow M, Zahn-Waxler C, Richardson DT, et al. Caring behavior in children of clinically depressed and well mothers. Child Dev 1994;65:1405-14.

21 Ibanez G, Bernard JY, Rondet C, et al. Effects of antenatal maternal depression and anxiety on children's early cognitive development: a prospective cohort study. PLoS One 2015;10:e0135849.

22 Van den Bergh BRH, Mennes M, Oosterlaan J, et al. High antenatal maternal anxiety is related to impulsivity during performance on cognitive tasks in 14- and 15-year-olds. Neurosci Biobehav Rev 2005;29:259-69.

23 Paulus M, Licata M, Kristen S, et al. Social understanding and selfregulation predict pre-schoolers' sharing with friends and disliked peers. Int J Behav Dev 2015;39:53-64.

24 Sodian B, Licata M, Kristen-Antonow S, et al. Understanding of goals, beliefs, and desires predicts morally relevant theory of mind: a longitudinal investigation. Child Dev 2016;87:1221-32.

25 Greig A, Howe D. Social understanding, attachment security of preschool children and maternal mental health. Br J Dev Psychol 2001;19:381-93.

26 Rohrer LM, Cicchetti D, Rogosch FA, et al. Effects of maternal negativity and of early and recent recurrent depressive disorder on children's false belief understanding. Dev Psychol 2011:47:170-81.

27 Sanger C, lles JE, Andrew CS, et al. Associations between postnatal maternal depression and psychological outcomes in adolescent offspring: a systematic review. Arch Womens Ment Health 2015;18:147-62.

28 Luoma I, Tamminen T, Kaukonen P, et al. Longitudinal study of maternal depressive symptoms and child well-being. J Am Acad Child Adolesc Psychiatry 2001;40:1367-74.

29 Nonnenmacher N, Noe D, Ehrenthal JC, et al. Postpartum bonding: the impact of maternal depression and adult attachment style. Arch Womens Ment Health 2016;19:927-35.

30 Thomas SR, O'Brien KA, Clarke TL, et al. Maternal depression history moderates parenting responses to compliant and noncompliant behaviors of children with ADHD. J Abnorm Child Psychol 2015;43:1257-69.

31 Mäntymaa M, Puura K, Luoma I, et al. Child's behaviour in motherchild interaction predicts later emotional and behavioural problems. Infant Child Dev 2009;18:455-67.

32 Stanley C, Murray L, Stein A. The effect of postnatal depression on mother-infant interaction, infant response to the Still-face perturbation, and performance on an instrumental learning task. Dev Psychopathol 2004;16:1-18.

33 Dietz LJ, Jennings KD, Kelley SA, et al. Maternal depression, paternal psychopathology, and toddlers' behavior problems. J Clin Child Adolesc Psychol 2009;38:48-61.

34 Tronick E, Reck C. Infants of depressed mothers. Harv Rev Psychiatry 2009;17:147-56.

35 Azak S, Raeder S. Trajectories of parenting behavior and maternal depression. Infant Behav Dev 2013;36:391-402.

36 Stein A, Craske MG, Lehtonen A, et al. Maternal cognitions and mother-infant interaction in postnatal depression and generalized anxiety disorder. J Abnorm Psychol 2012;121:795-809.

37 Zietlow A-L, Nonnenmacher N, Reck C, et al. Emotional stress during pregnancy - associations with maternal anxiety disorders, infant cortisol reactivity, and mother-child interaction at pre-school age. Front Psychol 2019;10:2179.

38 Müller M, Zietlow A-L, Tronick E, et al. What dyadic reparation is meant to do: an association with infant cortisol reactivity. Psychopathology 2015;48:386-99.

39 Beebe B, Lachmann F, Jaffe J. Mother-infant interaction structures and presymbolic self- and object representations. Psychoanal Dialogues 1997;7:133-82.

40 Weinberg MK, Tronick EZ. The impact of maternal psychiatric illness on infant development. J Clin Psychiatry 1998;59:53-61.

41 Diener ML, Mangelsdorf SC. Behavioral strategies for emotion regulation in toddlers: associations with maternal involvement and emotional expressions. Infant Behav Develop 1999;22:569-83.

42 Kopp CB. Regulation of distress and negative emotions: a developmental view. Dev Psychol 1989;25:343-54.

43 Gianino A, Tronick EZ. The mutual regulation model: The infant's self and interactive regulation and coping and defensive capacities. In: Field TM, McCabe PM, Schneiderman N, eds. Stress and coping across development. Hillsdale, NJ: Lawrence Erlbaum Associates, Inc, 1988: 47-68.

44 Tronick EZ. Emotions and emotional communication in infants. Am Psychol 1989;44:112-9.

45 Zijlmans MAC, Riksen-Walraven JM, de Weerth C. Associations between maternal prenatal cortisol concentrations and child outcomes: a systematic review. Neurosci Biobehav Rev 2015;53:1-24.

46 Van den Bergh BRH, van den Heuvel MI, Lahti M, et al. Prenatal developmental origins of behavior and mental health: the influence of maternal stress in pregnancy. Neurosci Biobehav Rev 2020;117:26-64.

47 Keller PS, El-Sheikh M, Granger DA, et al. Interactions between salivary cortisol and alpha-amylase as predictors of children's cognitive functioning and academic performance. Physiol Behav 2012;105:987-95.

48 Schumacher S, Kirschbaum C, Fydrich T, et al. Is salivary alphaamylase an indicator of autonomic nervous system dysregulations in mental disorders?--a review of preliminary findings and the interactions with cortisol. Psychoneuroendocrinology 2013;38:729-43.

49 Lewin A, Mitchell SJ, Waters D, et al. The protective effects of father involvement for infants of teen mothers with depressive symptoms. Matern Child Health J 2015;19:1016-23.

50 Yap MBH, Jorm AF. Parental factors associated with childhood anxiety, depression, and internalizing problems: a systematic review and meta-analysis. J Affect Disord 2015;175:424-40.

51 Yap MBH, Pilkington PD, Ryan SM, et al. Parental factors associated with depression and anxiety in young people: a systematic review and meta-analysis. J Affect Disord 2014;156:8-23.

52 Tanner Stapleton L, Bradbury TN. Marital interaction prior to parenthood predicts parent-child interaction 9 years later. $J$ Fam Psychol 2012;26:479-87.

53 Arbeitsgruppe Deutsche Child Behavior Checklist. Elternfragebogen für Klein- und Vorschulkinder (CBCL/1,5-5). köln: Arbeitsgruppe Kinder-, Jugend- und Familiendiagnostik (KJFD) 2000.

54 Reuner G, Rosenkranz J. Bayley-III - Bayley scales of infant and toddler development III: Deutsche Version. Frankfurt: Pearson Assessment \& Information $\mathrm{GmbH}, 2015$.

55 Weinberg MK, Beeghly M, Olson KL, et al. Effects of maternal depression and panic disorder on mother-infant interactive behavior in the face-to-face STILL-FACE paradigm. Infant Ment Health J 2008;29:472-91.

56 Martinez-Torteya C, Muzik M, McGinnis EW, et al. Longitudinal examination of infant baseline and reactivity cortisol from ages 7 to 16 months. Dev Psychobiol 2015;57:356-64.

57 Reck C, Zietlow A-L, Müller M, et al. Perceived parenting stress in the course of postpartum depression: the buffering effect of maternal bonding. Arch Womens Ment Health 2016;19:473-82. 
58 R Development Core Team. R: a language and environment for statistical computing. Vienna, Austria: R Foundation for Statistical Computing, 2008.

59 Beck CT. The effects of postpartum depression on child development: a meta-analysis. Arch Psychiatr Nurs 1998;12:12-20.

60 Margraf J, Cwik JC, Pflug V. Strukturierte klinische Interviews zur Erfassung psychischer Störungen über die Lebensspanne : Gütekriterien und Weiterentwicklungen der DIPS-Verfahren. Z Klin Psychol Psychother 2017;46:176-86.

61 Margraf J, Cwik JC, Suppiger A. Dips open access: Diagnostisches interview bei psychischen Störungen. Bochum: Mental Health Research and Treament Center, Ruhr-Universität Bochum, 2017.

62 Tronick E, Als H, Adamson L, et al. The infant's response to entrapment between contradictory messages in face-to-face interaction. J Am Acad Child Psychiatry 1978;17:1-13.

63 Hahlweg K. Fragebogen Zur Partnerschaftsdiagnostik (FPD): Partnerschaftsfragebogen (PFB). Göttingen: Hogrefe, 1996.

64 Goertz C, Knopf M, Kolling T. Der frankfurter Imitations-Test für 12 Monate alte Kinder (fit 12). Z Entwicklungspsychol Padagog Psychol 2006;38:88-96.

65 Mundy P, Delgado C, Block J. Early social communication scales (ESCS). Coral Gables, FL: University of Miami, 2003.

66 Camaioni L, Perucchini P, Bellagamba F. The role of declarative pointing in developing a theory of mind. Infancy 2004;5:291-308.

67 Arbeitsgruppe Deutsche child behavior checklist. Fragebogen für Erzieherinnen von Klein- und Vorschulkindern (C-TRF/1,5-5). köln: Arbeitsgruppe Kinder-, Jugend- und Familiendiagnostik (KJFD) 2000.

68 Gottman JM. What predicts divorce? The relationship between marital processes and marital outcomes. Hillsdale, New Jersey: Lawrence Erlbaum Associates, 1994.

69 Zietlow A-L, Eckstein M, Hernández C, et al. Dyadic Coping and Its Underlying Neuroendocrine Mechanisms - Implications for Stress Regulation. Front Psychol 2018;9:2600.

70 Ditzen B, Schaer M, Gabriel B, et al. Intranasal oxytocin increases positive communication and reduces cortisol levels during couple conflict. Biol Psychiatry 2009;65:728-31.

71 Feldman R, Masalha S. Parent-child and triadic antecedents of children's social competence: cultural specificity, shared process. Dev Psychol 2010;46:455-67.

72 Reck C, Noe D, Weinberg M. Infant and Caregiver Engagement Phases (ICEP-R) - German Revised Version. Heidelberg: Universitätsklinikum Heidelberg, 2009.

73 Schwartz EB, Granger DA, Susman EJ, et al. Assessing salivary cortisol in studies of child development. Child Dev 1998;69:1503-13.

74 Pruessner JC, Kirschbaum C, Meinlschmid G, et al. Two formulas for computation of the area under the curve represent measures of total hormone concentration versus time-dependent change. Psychoneuroendocrinology 2003;28:916-31.

75 Bifulco A, Moran PM, Ball C, et al. Adult attachment style. I: its relationship to clinical depression. Soc Psychiatry Psychiatr Epidemiol 2002;37:50-9.

76 Albers CA, Grieve AJ. Test review: Bayley, N. (2006). Bayley scales of infant and toddler development- third edition. San Antonio, TX: Harcourt assessment. J Psychoeduc Assess 2007;25:180-90.

77 Grimm H, Aktas M, Frevert S. Sprachentwicklungstest für zweijährige Kinder (SETK- 2). Göttingen: Hogrefe, 2000.

78 Paulus M, Kühn-Popp N, Licata M, et al. Neural correlates of prosocial behavior in infancy: different neurophysiological mechanisms support the emergence of helping and comforting. Neuroimage 2013;66:522-30.

79 Liew J, Eisenberg N, Spinrad TL, et al. Physiological regulation and Fearfulness as predictors of young children's Empathy-related reactions. Soc Dev 2011;20:111-3.
80 Bolin JH. Reviewed work: introduction to mediation, moderation, and conditional process analysis: a regression-based approach by Andrew F and Hayes (2013). J Educ Meas 2014;51:335-7.

81 Little RJA. A test of missing completely at random for multivariate data with missing values. J Am Stat Assoc 1988;83:1198-202.

82 Rubin DB. Multiple imputation for nonresponse in surveys. New York, NY: Wiley \& Sons, 1987.

83 Enders CK. Applied missing data analysis. New York: The Guilford Press, 2010.

84 Bergant AM, Nguyen T, Heim K, et al. Deutschsprachige Fassung und Validierung der "Edinburgh postnatal depression scale«. Dtsch Med Wochenschr 1998;123:35-40.

85 Ehlers A, Margraf J, Chambless D. Fragebogen zu körperbezogenen Ängsten, Kognitionen und Vermeidung (AKV). Göttingen: Beltz Test, 2001.

86 Reck C, Klier CM, Pabst K, et al. The German version of the postpartum bonding instrument: psychometric properties and association with postpartum depression. Arch Womens Ment Health 2006;9:265-71.

87 Fydrich T, Sommer G. Brähler E. F-SozU: Fragebogen Zur Sozialen Unterstützung. Göttingen: Hogrefe, 2007.

88 Gmelch S, Bodenmann G, Meuwly N. Dyadisches coping Inventar (DCl): ein Fragebogen Zur Erfassung des partnerschaftlichen Umgangs MIT stress. Z Fam Forsch 2008;20:185-203.

89 Schumacher J. FEE - Fragebogen zum erinnerten elterlichen Erziehungsverhalten. In: Brähler E, Schumacher J, Strauß B, eds. Diagnostik für Klinik und praxis, band 1. Göttingen: Hogrefe, 2002: 111-4.

90 Parker G, Tupling H, Brown LB. A parental bonding instrument. Br J Med Psychol 1979;52:1-10.

91 Ehrenthal JC, Dinger U, Lamla A. Evaluation der deutschsprachigen Version des Bindungsfragebogens "Experiences in Close Relationships-Revised" (ECR-RD). Psychother Psychosom Med Psychol 2009;59:215-23.

92 Pauli-Pott U, Ries-Hahn A, Kupfer J. Konstruktion eines Fragebogens zur Erfassung des "frühkindlichen Temperaments" im Elternurteil - Ergebnisse für den Altersbereich drei bis vier Monate. Prax Kinderpsychol Kinderpsychiatr 1999;48:231-46.

93 Zimmermann J, Altenstein D, Krieger T, et al. The structure and correlates of self-reported DSM-5 maladaptive personality traits: findings from two German-speaking samples. $J$ Pers Disord 2014;28:518-40.

94 Klinitzke G, Romppel M, Häuser W. Die deutsche Version des Childhood Trauma Questionnaire (CTQ) - psychometrische Eigenschaften in einer bevölkerungsrepräsentativen Stichprobe. Psychother Psychosom Med Psychol 2012;62:47-51.

95 Tröster H, Eltern-Belastungs-Inventar: EBI. Deutsche version des parenting stress index (PSI) von R. R. Abidin. Göttingen: Hogrefe 2010.

96 Bifulco A, Mahon J, Kwon JH, et al. The vulnerable attachment style questionnaire (VASQ): an Interview-Based measure of attachment styles that predict depressive disorder. Psychol Med 2003;33:1099-110.

97 Naumann S, Bertram H, Kuschel A. Der Erziehungsfragebogen (Efb): ein Fragebogen Zur Erfassung elterlicher Verhaltenstendenzen in schwierigen Erziehungssituationen. Diagnostica 2010;56:144-57.

98 Nolte T, Gingelmaier S, Schwarzer N-H. Epistemic trust questionnaire.

99 Luyten P, Mayes LC, Nijssens L, et al. The parental reflective functioning questionnaire: development and preliminary validation. PLoS One 2017; 12:e0176218. 